\begin{tabular}{|c|c|}
\hline Title & $\begin{array}{l}\text { A pseudoty pe vesicular stomatitis virus containing Hantaan virus envelope gly coproteins } G 1 \text { and } G 2 \text { as an al ternative to } \\
\text { hantavirus vaccine in mice }\end{array}$ \\
\hline Author(s) & Lee, Byoung-Hee; Yoshimatsu, Kumiko; A raki, Koichi; Okumura, Megumi; Nakamura, Ichiro; A rikawa, Jiro \\
\hline Citation & $\begin{array}{l}\text { V accine, 24(15), 2928.2934 } \\
\text { https://doi.org/10.1016/.vaccine.2005.12.040 }\end{array}$ \\
\hline Issue Date & $2006-04-05$ \\
\hline Doc URL & http:/hdl .handle.net/2115/8543 \\
\hline Type & article (author version) \\
\hline File Information & V ac-Jpn-0523_BH_Lee.pdf \\
\hline
\end{tabular}

Instructions for use 


\section{A pseudotype vesicular stomatitis virus containing Hantaan virus envelope glycoproteins G1 and G2 as an alternative to hantavirus vaccine in mice}

Byoung-Hee Lee, Kumiko Yoshimatsu, Koichi Araki, Megumi Okumura, Ichiro

$$
\text { Nakamura, Jiro Arikawa* }
$$

Institute for Animal Experimentation, Hokkaido University Graduate School of Medicine,

Sapporo 060-8638, Japan

*Address correspondence to: Professor Jiro Arikawa, D.V.M., Ph.D.

Institute for Animal Experimentation, Hokkaido University Graduate School of Medicine

Kita-15, Nishi-7, Kita-ku, Sapporo 060-8638, Japan

Tel: +81-11-706-6905; Fax: +81-11-706-7879; E-mail: j_arika@med.hokudai.ac.jp

Running head: Use of a pseudotype virion as a hantavirus vaccine 


\section{Abstract}

We examined whether a vesicular stomatitis virus (VSV) pseudotype bearing the hantavirus envelope glycoproteins (GPs) G1 and G2 (VSV $\left.\Delta \mathrm{G}^{*} \mathrm{HTN}\right)$ could be used as a safe and effective alternative to native hantavirus. Mice were immunized with purified particles of VSV $\Delta \mathrm{G}^{*} \mathrm{HTN}$. After the second immunization, all mice produced anti-GP antibody as detected in ELISA and a neutralization test. After the third immunization, the mice were challenged with Hantaan virus. Neither anti-NP antibody production nor Hantaan virus-specific CD8 T-cell reactions were detected in these mice. The present study demonstrated the potential of using a pseudotype VSV system as a tool for developing a hantavirus vaccine. (102 words)

Keywords: Envelope; Hantavirus; Pseudotype 


\section{Introduction}

Hemorrhagic fever with renal syndrome (HFRS) and hantavirus pulmonary syndrome (HPS) are rodent-borne viral zoonoses caused by viruses in the Hantavirus genus of the Bunyaviridae family. Among the 22 currently registered virus species within the genus, the Hantaan virus (HTNV), Seoul virus (SEOV), Dobrava virus, and Puumala virus (PUUV) are causative agents of HFRS in Eurasia, while the Sin Nombre virus, Andes virus, New York virus, and other related viruses are known to cause HPS in North and South America $[1]$.

Each virus species is carried by a specific rodent species in nature, thus restricting the virus' prevalence to the regions populated by these rodents $[1,2]$. HFRS has been reported throughout Eurasia and particularly in China, where tens of thousands of cases are reported annually [3]. In addition, thousands of cases have been reported in Europe and Far East Asia [4], and several hundred have been reported in both North and South America [1]. The mortality rates of HFRS and HPS patients are $0.1-10 \%$ and around $40 \%$, respectively [1]. Thus, both HFRS and HPS are important zoonoses from a public health perspective. Hantaviruses contain a single-stranded, negative-sense RNA genome that is divided 
into three segments, designated large (L), medium (M), and small (S) [5]. The L segment encodes RNA-dependent RNA polymerase. The S segment encodes nucleocapsid protein (NP), and the M segment encodes a glycoprotein (GP) precursor that is cotranslationally cleaved into the envelope proteins G1 and G2 [5]. The G1 and G2 proteins form projections on the virion surface, induce low-pH dependent cell fusion [6], and are the targets of neutralizing antibodies $[7,8]$.

Inactivated HTNV, SEOV, or PUUV vaccines prepared from the viruses grown in suckling mouse brain or tissue culture cells have been developed in Korea and China [9-11]. Although limited efficacy has been observed, attempts have been made to develop recombinant protein-based vaccines that reduce or eliminate biohazard risks during preparation as well as achieve higher efficacy. Immunizations with recombinant G1 and G2 proteins expressed by baculovirus and vaccinea virus induce very low or negligible amounts of neutralizing antibody [12-14]. Although the antibody titers are high, this low efficacy for inducing neutralizing antibody may be attributable to the incorrect conformation of the recombinant G1 and G2 compared to the native proteins.

We recently expressed the G1 and G2 of HTNV using a mammalian cell expression 
vector. In addition, by supplying the G1 and G2 proteins in trans to the infected cells with recombinant vesicular stomatitis virus (VSV), whose envelope G protein was altered to enhanced green fluorescent protein (eGFP), we generated the pseudotype VSV (pVSV), which possesses the HTNV envelope proteins G1 and G2 (VSV $\left.\Delta \mathrm{G}^{*} \mathrm{HTN}\right)$ [15]. Infection by VSV $\Delta \mathrm{G}^{*} \mathrm{HTN}$ was inhibited by neutralizing monoclonal antibodies (MAbs) and patient sera. The neutralizing antibody titers were virtually identical to those measured with native virus. These results indicated that the structure and function of the expressed G1 and G2 effectively mimics the native viral proteins. Based on these results, we examined the applicability of pVSV as a possible tool for producing inactivated vaccine that may induce neutralizing antibody more efficiently than the previously examined recombinant proteins.

\section{Materials and methods}

\subsection{Viruses and cells}

HTNV strain 76-118 was propagated in the Vero cell E6 clone (ATCC C1008). The 293 T cell is derived from the human embryonic kidney cell line 293 and contains the 
simian virus 40 large T antigen. The 293T cells were maintained in Dulbecco's modified Eagle's medium (DMEM; Nissui, Tokyo, Japan) supplemented with $0.45 \%$ glucose and $10 \%$ heat-inactivated fetal calf serum (FCS). The recombinant baculovirus for expressing HTNV viruses G1 and G2 was kindly supplied by Dr. C. S. Schmaljohn [12] and was propagated in High Five ${ }^{\mathrm{TM}}$ cells.

\subsection{Mice}

Specific-pathogen-free, six-week-old female BALB/c/slc mice were obtained from SLC (Hamamatsu, Japan). All mice were treated in accordance with the laboratory animal control guidelines of our institute, which conform to those of the U.S. National Institutes of Health. All experiments were conducted in a BSL class P3 facility.

\subsection{Production of pseudotype VSV}

Pseudotype VSV containing HTNV G1 and G2 (VSVAG*HTN) or the G protein of VSV (VSV $\Delta \mathrm{G}^{*} \mathrm{G}$ ) was prepared in $293 \mathrm{~T}$ cells as previously described [15]. Briefly, $36 \mathrm{~h}$ 
after the transfection of $293 \mathrm{~T}$ cells with expression vectors based on pCAGGS/MCS containing the coding information of the glycoproteins of Hantaan virus, Seoul virus, or G protein of VSV, the cells were infected with $\mathrm{VSV} \Delta \mathrm{G}^{*} \mathrm{G}$ at a multiplicity of infection (MOI) of 1 for $1 \mathrm{~h}$ at $37^{\circ} \mathrm{C}$. VSV $\Delta \mathrm{G}^{*} \mathrm{G}$, whose genome had the enhanced GFP gene instead of the G protein, was kindly provided by Dr. Michael A. Whitt. The 293T cell monolayer was then washed with $1 \%$ heat-inactivated FCS-PBS three times, and culture medium was added. After a $24-\mathrm{h}$ incubation at $37^{\circ} \mathrm{C}$ in a $\mathrm{CO}_{2}$ incubator, the culture supernatant was clarified by low-speed centrifugation and stored at $-80^{\circ} \mathrm{C}$.

\subsection{Purification of pseudotype VSV}

The culture supernatant containing pseudotype VSV was purified by ultracentrifugation at $100,000 \mathrm{rpm}$ for $1 \mathrm{~h}$ through a $20-60 \%$ sucrose cushion in TNE buffer ( $10 \mathrm{mM}$ Tris, 135 $\mathrm{mM} \mathrm{NaCl}, 2 \mathrm{mM}$ EDTA) with a type-50 titanium rotor in a Beckman L-80 ultracentrifuge (Beckman Instruments, Palo Alto, CA). Virions were recovered from the sucrose cushion and measured as the hemagglutination (HA) activity of goose erythrocytes [16,17]. 


\subsection{Titration of pseudotype VSV}

Vero E6 cells grown on eight-well slides were infected with $50 \mu \mathrm{L}$ of serially diluted virus stock. After a 1-h adsorption period, the inoculum was removed; fresh culture medium was added, and the cells were incubated at $37^{\circ} \mathrm{C}$ in a $\mathrm{CO}_{2}$ incubator. At $16 \mathrm{~h}$ postinfection, the cells were fixed with $10 \%$ formalin in PBS for $10 \mathrm{~min}$ at room temperature, washed with distilled water, and air-dried. Fluorescent GFP-expressing cells were counted under a fluorescence microscope. Because pseudotype VSV is unable to produce infectious progeny, the numbers of GFP-positive cells were regarded as infectious units (IU).

\subsection{Immunization and sample collection}

Eight mice were immunized subcutaneously three times at intervals of 3 and 2 weeks after the first immunization (Fig. 1) with purified particles of VSV $\Delta \mathrm{G}^{*} \mathrm{HTN}\left(1 \mathrm{X} 10^{7} \mathrm{IU} /\right.$ 
mouse/50 $\mu \mathrm{l}$ ) mixed with $50 \mu \mathrm{l}$ of $\mathrm{CpG}$ DNAadjuvant (ImmunEasy Mouse Adjuvant;

Qiagen GmbH, Hilden, Germany). The adjuvant contained immunostimulatory $\mathrm{CpG}^{\mathrm{TM}}$ DNA short oligonucleotides that had unmethlylated cytosine-guanine dinucleotides within a certain base context. Four mice were immunized with $\mathrm{VSV} \Delta \mathrm{G}^{*} \mathrm{G}$ as controls. Fifty microliters of blood was collected from the mice under ether anesthesia, at the intervals described in Fig. 1 by retro-orbital plexus puncture. The blood was immediately mixed with $200 \mu \mathrm{L}$ of PBS and centrifuged to remove blood cells. The supernatant represented an approximately 1:10 dilution of serum. The sera were inactivated by exposure at $56^{\circ} \mathrm{C}$ for $30 \mathrm{~min}$. All serum specimens were stored at $-30^{\circ} \mathrm{C}$ prior to antibody titration. After 3 weeks of HTNV inoculation, the spleen was collected under ether anesthesia. Spleen single-cell suspensions were obtained using previously published methods [18] and stored at $-80^{\circ} \mathrm{C}$ in freezing medium (Cell Banker; Jujin, Tokyo, Japan) prior to CD8 $\mathrm{T}$ cell analysis.

\subsection{HTNV infection}

Seven groups of six, six-week-old female BALB/c mice were inoculated 
intraperitoneally with various doses $\left(10^{-3}-10^{-8}\right.$ dilution $)$ of HTNV diluted in PBS, and the antibody responses were examined 3 weeks after inoculation. Based on the ratio of seropositive mice, the $\mathrm{ID}_{50}$ of HTNV was determined as 0.127 focus-forming units (FFU). Mice were inoculated with 4.0 FFU of HTNV in the challenge experiment.

\subsection{Purification and papain digestion of MAb clone 11E10-2-2}

MAb clone 11E10-2-2, which recognizes G2 of HTNV [7], was purified by protein A column chromatography (Affi-Gel, MOPS II kit; Bio-Rad, Hercules, CA). To prepare the Fab fragment of the MAb, purified IgG was digested with papain (P-3125; Sigma-Aldrich, St. Louis, MO) as previously described [19]. Briefly, papain digestion was performed with an enzyme-to-antibody ratio of 1:400 in standard PBS buffer containing $3 \mathrm{mM}$ EDTA and $10 \mathrm{mM}$-cysteine at $37^{\circ} \mathrm{C}$. The reaction was stopped with the addition of fresh iodoacetamide solution to a final concentration of $10 \mathrm{mM}$ followed by incubation in the dark at $4{ }^{\circ} \mathrm{C}$ for $30 \mathrm{~min}$. The digested MAb was then passed through Protein A columns under the same experimental conditions used for the purification of IgG. The unbound 
fraction (Fab fragment) and bound fractions (Fc fragment and undigested $\operatorname{IgG}$ ) were analyzed by SDS-polyacrylamide gel electrophoresis (SDS-PAGE).

\subsection{ELISA}

To detect antibody specific to HTNV GP, ELISA was performed using the Fab fraction of MAb 11E10-2-2, which was directed to HTNV GP as the capture antibody. The 96-well microtiter plates (FALCON 3915; Falcon, Franklin Lakes, NJ) were coated with Fab of MAb 11E10-2-2 $(50 \mu \mathrm{g} / \mathrm{ml})$ in PBS and incubated at $4^{\circ} \mathrm{C}$ overnight. After three washes with PBS containing 0.05\% Tween-20 (PBS-T; Wako, Osaka, Japan), High Five ${ }^{\mathrm{TM}}$ cell lysate containing recombinant GP as previously described [20] was added to the plates for $1 \mathrm{~h}$ at $37^{\circ} \mathrm{C}$. After washing three times with PBS-T, the wells were filled with Block Ace (Yukijirushi, Tokyo, Japan), incubated at room temperature for $30 \mathrm{~min}$, and washed again. The mouse sera were diluted at 1:200 with ELISA buffer containing PBS-T with $0.5 \%$ BSA (A-4503; Sigma-Aldrich) and were then added to the wells. The plates were incubated at $37^{\circ} \mathrm{C}$ for $1 \mathrm{~h}$ and washed three times with PBS-T. Bound antibodies were detected with 0.5 
$\mu \mathrm{g} / \mathrm{ml}$ Protein A-horseradish peroxidase conjugate (Biogenesis, San Leandro, CA) in ELISA buffer. Wells were developed with $100 \mu$ of substrate solution, which contained $10 \mathrm{mg}$ o-phenylenediamine (Sigma-Aldrich) plus $6 \mathrm{ml}$ of $0.02 \% \mathrm{H}_{2} \mathrm{O}_{2}$ (Wako). After a 15-min incubation in the dark at room temperature, the absorbance at $450 \mathrm{~nm}$ was read using a microplate spectrophotometer (Spectra Max 340; Molecular Devices, Sunnyvale, CA). For ELISA to detect antibody specific to NP, recombinant HTNV NP was used as the antigen. The ELISA procedure was as previously described [21].

\subsection{Focus reduction neutralization test}

The focus reduction neutralization test (FRNT) using HTNV and Vero E6 cells was performed as previously described [22]. The FRNT titer was expressed as the reciprocal of the highest dilution that gave a reduction of greater than $80 \%$ in the number of infected cell foci. 


\subsection{Detection of HTNV-specific CD8 ${ }^{+}$T cells}

To detect HTNV-specific $\mathrm{CD}^{+} \mathrm{T}$ cells, we used flow cytometry to assay for intracellular gamma interferon (IFN- $\gamma$ ) of $\mathrm{CD}^{+} \mathrm{T}$ cells stimulated by incubation with HTNV-infected antigen-presenting cells, as previously described [18].

\section{Results}

3.1. ELISA and FRNT antibody responses in mice immunized with pseudotype VSV

The antibody responses of mice immunized with pseudotype VSVs were measured by ELISAs for specific antibodies to HTNV GP (Fig. 2) or to HTNV NP (Fig. 3). Although FRNT antibody was not detected in any mice except one at 3 weeks after the first immunization with VSV $\Delta \mathrm{G}^{*} \mathrm{HTN}$, a low level of anti-GP antibody was detected in a few mice compared to control mice immunized with $\mathrm{VSV}_{\Delta \mathrm{G}}^{*} \mathrm{G}$ or PBS (Table 1, Fig. 2). After the second immunization, all mice immunized with $\mathrm{VSV} \Delta \mathrm{G}^{*} \mathrm{HTN}$ possessed both FRNT 
antibody and anti-GP antibody as detected by ELISA (Table 1, Fig. 2). However, NP-specific antibody induction was not detected in any of the mice inoculated with $\mathrm{VSV} \Delta \mathrm{G}^{*} \mathrm{HTN}, \mathrm{VSV} \Delta \mathrm{G}^{*} \mathrm{G}$, or PBS alone (Fig. 3). These results indicated that VSV $\Delta \mathrm{G}^{*} \mathrm{HTN}$ was able to induce GP-specific antibody in mice.

The neutralizing activity of the GP-specific antibody was measured using the $80 \%$ FRNT. As summarized in Table 1, all eight mice immunized with VSV $\Delta \mathrm{G}^{*} \mathrm{HTN}$ developed FRNT antibody at titers ranging from 1:40 to 1:160 within 2 weeks after the second immunization. All control mice inoculated with either VSV $\Delta \mathrm{G}^{*} \mathrm{G}$ or PBS alone were negative for FRNT antibody.

3.2. Evaluation of protective immunity induced by pseudotype VSV for preventing HTNV challenge in mice

To assess the protective immunity, mice were challenged with HTNV at 1 week after the third immunization (Fig. 1). Although exceptional fatal infection models in adult mice have been reported $[23,24]$, hantavirses are generally nonpathogenic to mature rodents. In 
this study, we used a general Hantaan virus strain. Therefore, it is difficult to evaluate protective immunity. To differentiate the antibody response induced by immunization from that induced by HTNV infection, seroconversion against NP accompanied with the establishment of infection was used as an index for protection (Fig. 2). In addition, the HTNV-specific $\mathrm{CD}^{+} \mathrm{T}$ cell response was also measured as an index of protection. All mice immunized with VSV $\Delta \mathrm{G}^{*} \mathrm{HTN}$ remained negative for anti-NP antibody in ELISA, and no detectable level of HTNV-specific $\mathrm{CD}^{+} \mathrm{T}$ cells was observed in spleen cells at 3 weeks after the challenge (Fig. 4), indicating that the mice were protected from HTNV infection. In contrast, seroconversion was detected in VSV $\Delta \mathrm{G}^{*} \mathrm{G}$-immunized mice and in PBS control mice. Furthermore, a significant number of HTNV-specific $\mathrm{CD} 8^{+} \mathrm{T}$ cells was observed only in the control mice. These results indicate that protective immunity was not induced in these mice, confirming that immunization with VSV $\Delta \mathrm{G}^{*} \mathrm{HTN}$ conferred protective immunity.

\section{Discussion}

In general, virus proteins that are targeted by vaccines are observed on the outer 
surfaces of the virions or the envelope proteins. In addition, it is well-known that the structure of viruslike particles (VLPs) in combination with envelope proteins strengthens their immunogenicity. Therefore, the combination of VLPs and envelope proteins was expected to be an effective material for vaccine development. VLPs with recombinant hepatitis B surface proteins expressed in yeast provided a remarkably successful application for vaccine development [25]. Chimeric HBc particles with the hantavirus NP sequence have been reported to induce high antibody titer to NP, as well as to confer protective immunity in mice models [26]. However, similar applications have not been reported with hantavirus GPs.

In our previous study, we succeeded in producing VSV pseudotypes bearing hantavirus GPs, and these GPs were considered to have structures similar to those of native hantavirus GPs based on neutralization pattern profiling of Mabs and polyclonal antibodies [15]. Furthermore, because the pseudotype VSV lacks a gene for GP, it also lacks replication activity. Therefore, we anticipated that the pseudotype virion could be applicable as a safe alternative to authentic virion for use in vaccines. In this study, we used the particle of pseudotype VSV $\Delta \mathrm{G}^{*} \mathrm{HTN}$ as a type of VLP and examined its antigenicity in a mouse 
model.

Epitope analyses of GPs using MAbs against G1 and G2 showed that both G1 and G2 were associated with the FRNT-related epitope. The FRNT-related epitope was composed of partially overlapping epitopes on G1 and G2 [7,27,28] and might be related to the inhibition of the membrane fusion step [6]. In this study, we measured only anti-GP2 antibody in the ELISA because of the difficulty with the methodology. Because the FRNT epitopes on G1 and G2 overlap each other, it was expected that anti-G2 antibody was related to the rise in anti-G1 antibody. Actually, anti-G2 antibodies were correlated to FRNT titers as shown in Table 1.

As observed in this study, the pseudotype VSV $\Delta \mathrm{G}^{*} \mathrm{HTN}$ was able to induce neutralizing antibody with titers comparable to those reported for inactivated vaccines in humans as well as for recombinant proteins in the mouse model $[10,11,29]$. Furthermore, the pseudotype VSV $\Delta \mathrm{G}^{*} \mathrm{HTN}$ conferred protective immunity for hantavirus challenge in the mouse model. The fact that an HTNV-specific CD8 T-cell response was not observed in immunized mice after challenge also confirmed that the induced neutralizing antibody alone was effective for protection from the challenge inoculation. This is the first 
successful application of pseudotype VSV as a type of VLP for the induction of protective immunity. Few studies on the application of pseudotype virus as a vaccination antigen have been reported. In hepatitis type C virus (HCV), pseudotype virus was developed and applied to analyze virus-cell interactions and the assembly of virus particles [30,31]. Beynes et al. [32] tried to apply pseudotype VSV incorporating the envelope glycoprotein of $\mathrm{HCV}$ to vaccine development. In their experiment, neutralization antibody against pseudotype virus was successfully induced; however, there is no system for detecting neutralizing and protective activity against authentic HCV in vitro or in vivo [32].

Although an inactivated hantavirus vaccine has been developed and a protective efficacy comparable to those of other virus vaccines has been reported, low efficacy for the induction of neutralizing antibody remains an important aspect to be overcome [9-11,29]. Further studies are needed to clarify the potential of the pseudotype VSV with HTNV GPs as a useful tool for the development of hantavirus vaccine. It has been reported that the $\mathrm{M}$ protein of VSV strongly induces budding. The characteristics of VSV M protein suggest that the pseudotype VSV system could be applied to other viruses for which VLP development has been unsuccessful. 
Owing to the structural complexity of HTNV GP, a component vaccine made from recombinant GP proteins has not been developed. However, DNA vaccine trials have been reported [8] in which the DNA vaccine was able to induce a significantly high level of FRNT antibody in animals; this indicates that the recombinant GP expressed in mammalian cells possesses sufficient antigenicity to induce FRNT antibody. These results also imply that the fixation step during the preparation of inactivated hantavirus vaccine may be responsible for the preservation of antigenicity of the inactivated vaccine. The pseudotype virion used here could be developed as a useful tool with which to evaluate fixation methods for virus particles. By comparing the immunogenicity of unfixed and fixed pseudotype virions, we were able to estimate the damage done to GP molecules by fixation during the preparation of the hantavirus vaccine. Careful examination of the appropriate fixation conditions for inactivated vaccines may lead to higher efficacy.

The pseudotype VSV used in this study can replicate to express reporter genes, such as GFP, and exhibit a cytopathic effect. Therefore, for the practical application of pseudotype virion to vaccine, the development of VLPs lacking a replication system and containing HTNV Gps or VSV M protein should be pursued. 


\section{Acknowledgments}

We thank Dr. C. S. Schmaljohn for providing the recombinant baculovirus for expressing the HTNV GPs. This study was partly supported by a grant from the $21 \mathrm{st}$ Century COE Program of Excellence for Zoonosis Control from the Ministry of Education, Culture, Sports, Science and Technology of Japan. 
Table 1

Neutralizing antibody responses of mice immunized with VSV $\Delta \mathrm{G}^{*} \mathrm{HTN}$

Titer for $80 \%$ FRNT

Antigen Mouse ID 1stimm. 2ndimm. Post-challenge Protection

$\begin{array}{ccccc}2 & <40 & 40 & 40 & \text { Yes } \\ 2 & <40 & 40 & 80 & \text { Yes } \\ 3 & <40 & 40 & 80 & \text { Yes } \\ 4 & <40 & 40 & 80 & \text { Yes } \\ 5 & 40 & 80 & 80 & \text { Yes } \\ 6 & <40 & & & \\ 7 & <40 & 160 & 160 & \text { Yes } \\ 7 & <40 & 160 & 80 & \text { Yes } \\ 8 & & & & \text { Yes }\end{array}$


Vac-Jpn-05-23

\begin{tabular}{|c|c|c|c|c|c|}
\hline \multirow[t]{4}{*}{$\mathrm{VSV} \Delta \mathrm{G}^{*} \mathrm{G}$} & 1 & $<40$ & $<40$ & 40 & No \\
\hline & 2 & $<40$ & $<40$ & 160 & No \\
\hline & 3 & $<40$ & $<40$ & 160 & No \\
\hline & 4 & $<40$ & $<40$ & 80 & No \\
\hline \multirow[t]{4}{*}{ PBS } & 1 & $<40$ & $<40$ & 80 & No \\
\hline & 2 & $<40$ & $<40$ & 80 & No \\
\hline & 3 & $<40$ & $<40$ & 80 & No \\
\hline & 4 & $<40$ & $<40$ & 80 & No \\
\hline
\end{tabular}




\section{REFERENCES}

1 Schmaljohn, C. \& Hjelle, B. Hantaviruses - a Global Disease Problem. Emerging Infectious Diseases 1997, 3(2), 95-104.

2 Plyusnin, A., Vapalahti, O. \& Lundkvist, A. Hantaviruses: genome structure, expression and evolution. J Gen Virol 1996, 77(11), 2677-2687.

3 Song, G. Epidemiological progresses of hemorrhagic fever with renal syndrome in China. Chin Med J (Engl) 1999, 112(5), 472-477.

4 Lee, H.W. Epidemiology and pathogenesis of hemorrhagic fever with renal syndrome. In The bunyaviridae (Ed. Elliott, R.M.) Plenum Press, New York, 1996. 253-267.

5 Schmaljohn, C.S. \& Hooper, J.W. Bunyaviridae: the viruses and their replication. In Fields Virology, 4th ed. (Ed. Knipe, D.M.) Lippincott Williams \& Wilkins, Philadelphia, 2001. 1581-1602.

6 Ogino, M., Yoshimatsu, K., Ebihara, H., Araki, K., Lee, B.H., Okumura, M. et al. Cell fusion activities of Hantaan virus envelope glycoproteins. J Virol 2004, 78(19), 10776-10782.

7 Arikawa, J., Schmaljohn, A.L., Dalrymple, J.M. \& Schmaljohn, C.S. Characterization of Hantaan virus envelope glycoprotein antigenic determinants defined by monoclonal antibodies. J Gen Virol 1989, 70(3), 615-624.

8 Hooper, J.W., Kamrud, K.I., Elgh, F., Custer, D. \& Schmaljohn, C.S. DNA vaccination with Hantavirus $M$ segment elicits neutralizing antibodies and protects against Seoul virus infection. Virology 1999, 255(2), 269-278.

9 Hantavirus Vaccine Development. Bulletin of the World Health Organization 1996, 74(3), 336-337. 
10 Lee, H.W., Ahn, C.N., Song, J.W., Baek, L.J., Seo, T.J. \& Park, S.C. Field trial of an inactivated vaccine against hemorrhagic fever with renal syndrome in humans. Arch Virol Suppl 1990, 1, 35-47.

11 Song, G., Huang, Y.C., Hang, C.S., Hao, F.Y., Li, D.X., Zheng, X.L. et al. Preliminary human trial of inactivated golden hamster kidney cell (GHKC) vaccine against haemorrhagic fever with renal syndrome (HFRS). Vaccine 1992, 10(4), 214-216.

12 Schmaljohn, C.S., Arikawa, J., Dalrymple, J.M. \& Schmaljohn, A.L. Expression of the envelope glycoprotein of Hantaan virus with vaccinia and baculovirus recombinants. In Genetics and Pathgenicity of Negative Strand Viruses (Eds. Kolakofsky, D. \& Mahy, B.W.J.) Elsevier, Amsterdam; NewYork, 1989. 58-66.

13 Schmaljohn, C.S., Chu, Y.K., Schmaljohn, A.L. \& Dalrymple, J.M. Antigenic subunits of Hantaan virus expressed by baculovirus and vaccinia virus recombinants. $J$ Virol 1990, 64(7), 3162-3170.

14 Yoshimatsu, K., Yoo, Y.C., Yoshida, R., Ishihara, C., Azuma, I. \& Arikawa, J. Protective immunity of Hantaan virus nucleocapsid and envelope protein studied using baculovirus-expressed proteins. Arch Virol 1993, 130(3-4), 365-376.

15 Ogino, M., Ebihara, H., Lee, B.H., Araki, K., Lundkvist, A., Kawaoka, Y. et al. Use of vesicular stomatitis virus pseudotypes bearing hantaan or seoul virus envelope proteins in a rapid and safe neutralization test. Clin Diagn Lab Immunol 2003, 10(1), 154-160.

16 Clarke, D.H. \& Casals, J. Techniques for hemagglutination and hemagglutination-inhibition with arthropod-borne viruses. Am J Trop Med Hyg $1958,7(5), 561-573$.

17 Okuno, Y., Yamanishi, K., Takahashi, Y., Tanishita, O., Nagai, T., Dantas, J.R., Jr. et al. Haemagglutination-inhibition test for haemorrhagic fever with renal 
syndrome using virus antigen prepared from infected tissue culture fluid. Journal of General Virology 1986, 67(Pt 1), 149-156.

18 Araki, K., Yoshimatsu, K., Lee, B.-H., Kariwa, H., Takashima, I. \& Arikawa, J. Hantavirus-specific CD8+ T cell responses in newborn mice persistently infected with Hantaan virus. J. Virol. 2003, 77(15), 8408-8417.

19 Casale, E., Wenisch, E., He, X.M., Righetti, P.G., Snyder, R.S., Jungbauer, A. et al. Crystallization of the Fab from a human monoclonal antibody against gp 41 of human immunodeficiency virus type I. J Mol Biol 1990, 216(3), 511-512.

20 Yoshimatsu, K., Lee, B.H., Araki, K., Morimatsu, M., Ogino, M., Ebihara, H. et al. The multimerization of hantavirus nucleocapsid protein depends on type-specific epitopes. J Virol 2003, 77(2), 943-952.

21 Lee, B.H., Yoshimatsu, K., Araki, K., Ogino, M., Okumura, M., Tsuchiya, K. et al. Detection of antibody for the serodiagnosis of hantavirus infection in different rodent species. Arch Virol 2003, 148(10), 1885-1897.

22 Araki, K., Yoshimatsu, K., Ogino, M., Ebihara, H., Lundkvist, A., Kariwa, H. et al. Truncated hantavirus nucleocapsid proteins for serotyping Hantaan, Seoul, and Dobrava hantavirus infections. Journal of Clinical Microbiology 2001, 39(7), 2397-2404.

23 Asada, H., Balachandra, K., Tamura, M., Kondo, K. \& Yamanishi, K. Cross-reactive immunity among different serotypes of virus causing haemorrhagic fever with renal syndrome. J Gen Virol 1989, 70(Pt 4), 819-825.

24 Wichmann, D., Grone, H.J., Frese, M., Pavlovic, J., Anheier, B., Haller, O. et al. Hantaan virus infection causes an acute neurological disease that is fatal in adult laboratory mice. J Virol 2002, 76(17), 8890-8899.

25 Hollinger, F.B., Troisi, C.L. \& Pepe, P.E. Anti-HBs responses to vaccination with a 
human hepatitis B vaccine made by recombinant DNA technology in yeast. $J$ Infect Dis 1986, 153(1), 156-159.

26 Ulrich, R., Lundkvist, A., Meisel, H., Koletzki, D., Sjolander, K.B., Gelderblom, H.R. et al. Chimaeric Hbv Core Particles Carrying a Defined Segment Of Puumala Hantavirus Nucleocapsid Protein Evoke Protective Immunity In an Animal Model. Vaccine 1998, 16(2-3), 272-280.

27 Wang, M., Pennock, D.G., Spik, K.W. \& Schmaljohn, C.S. Epitope mapping studies with neutralizing and non-neutralizing monoclonal antibodies to the G1 and G2 envelope glycoproteins of Hantaan virus. Virology 1993, 197(2), 757-766.

28 Kikuchi, M., Yoshimatsu, K., Arikawa, J., Yoshida, R., Yoo, Y.C., Isegawa, Y. et al. Characterization of neutralizing monoclonal antibody escape mutants of Hantaan virus 76118. Archives of Virology 1998, 143(1), 73-83.

29 Yamanishi, K., Tanishita, O., Tamura, M., Asada, H., Kondo, K., Takagi, M. et al. Development of inactivated vaccine against virus causing haemorrhagic fever with renal syndrome. Vaccine 1988, 6(3), 278-282.

30 Matsuura, Y., Tani, H., Suzuki, K., Kimura-Someya, T., Suzuki, R., Aizaki, H. et al. Characterization of pseudotype VSV possessing HCV envelope proteins. Virology 2001, 286(2), 263-275.

31 Meyer, K., Basu, A. \& Ray, R. Functional features of hepatitis C virus glycoproteins for pseudotype virus entry into mammalian cells. Virology 2000, 276(1), 214-226.

32 Beyene, A., Basu, A., Meyer, K. \& Ray, R. Hepatitis C virus envelope glycoproteins and potential for vaccine development. Vox Sang 2002, 83 Suppl 1, 27-32. 


\section{Figure legends}

Fig. 1. Schedule of experiment. Immunizations with $V S V \Delta G^{*} H T N, V S V \Delta G * G$, or PBS are shown as closed triangles. The collection of serum samples is shown as open triangles.

Fig. 2. Antibody responses against hantavirus GP before challenge inoculation. Anti-GP antibodies were measured using ELISA; the recombinant GP was expressed in insect cells by the baculovirus vector system as described in the Materials and methods section. The positive control was serum from a hyperimmune mouse experimentally inoculated with HTNV. The negative control was serum from an uninfected mouse.

Fig. 3. Antibody responses against HTNV N protein after challenge inoculation. Anti-N protein antibodies were measured using ELISA; recombinant NP was expressed in Escherichia coli as described in the Materials and methods section. The positive control was serum from a hyperimmune mouse experimentally inoculated with HTNV. The negative control was serum from an uninfected mouse. 
Fig. 4. HTNV-specific CD8+ T cell responses after challenge inoculation. HTNV-specific CD8+ T cells were counted as IFN-gamma-producing cells; values are expressed as percent of total splenic CD8+ T cells.

A horizontal broken line indicates the limitation of the background level in this assay. 


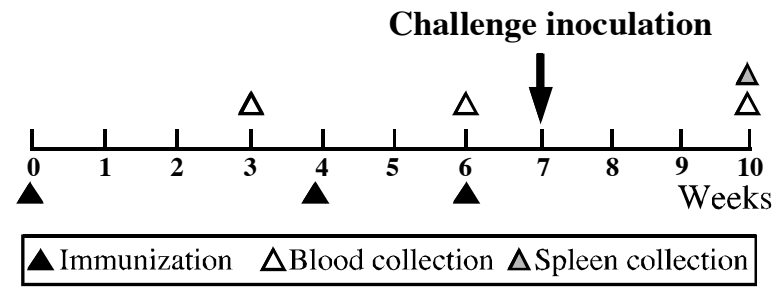

Fig. 1 B-H. Lee et al 


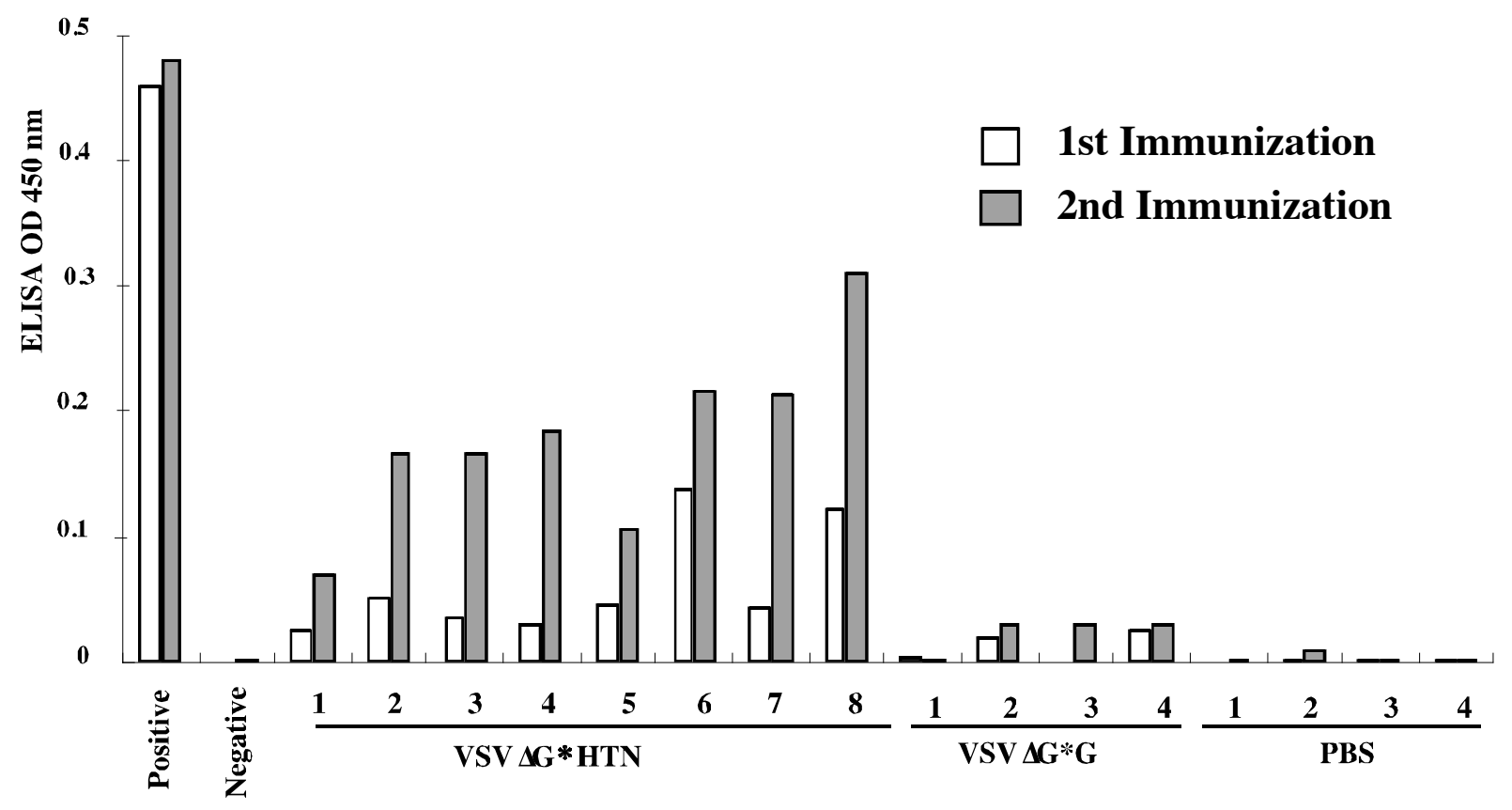

Fig. 2 B-H. Lee et al 


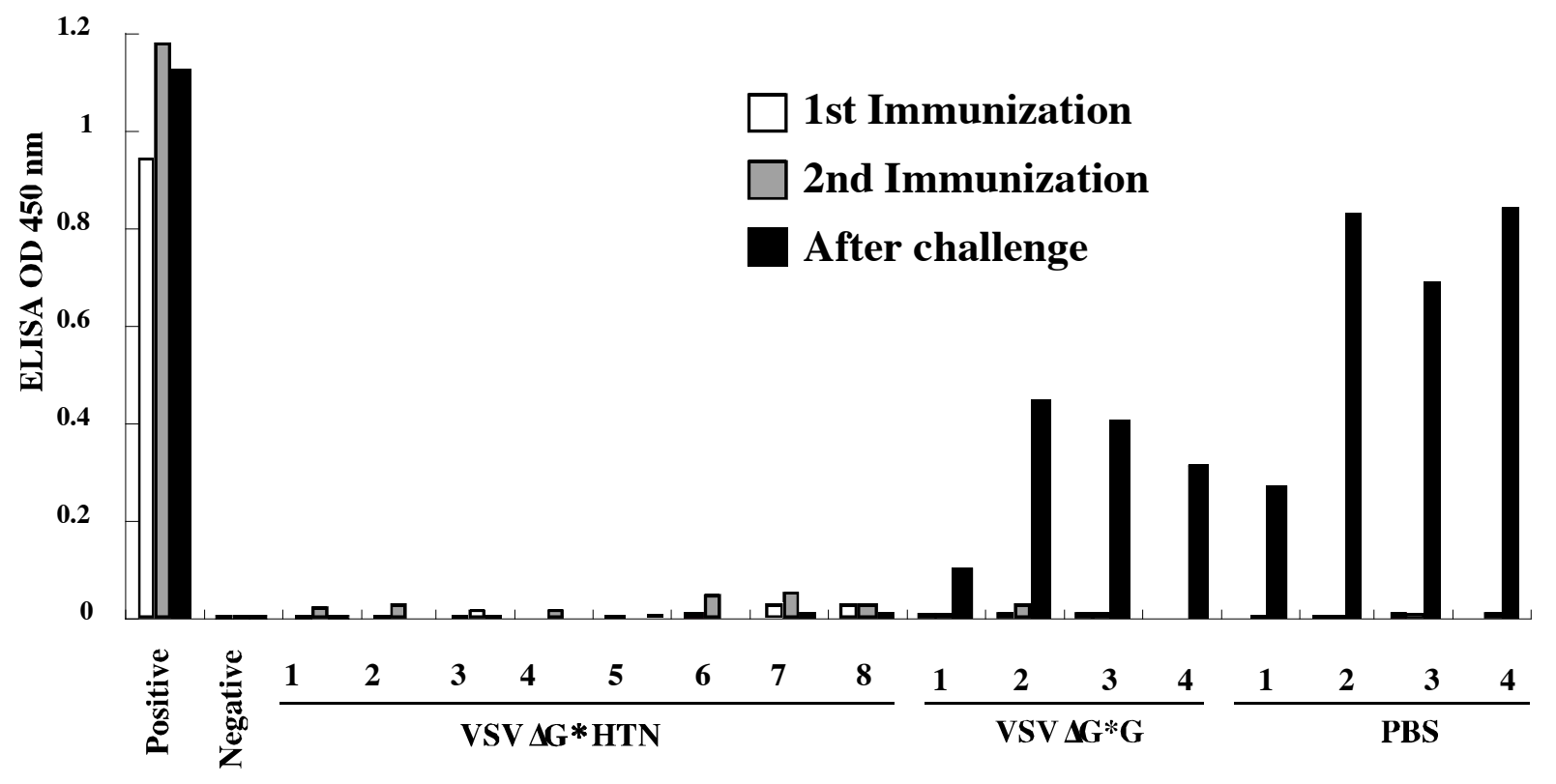

Fig. 3 B-H. Lee et al 


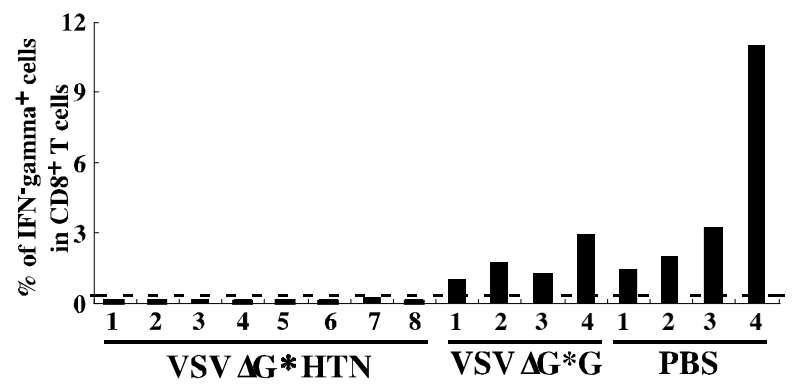

Fig. 4 B-H. Lee et al 